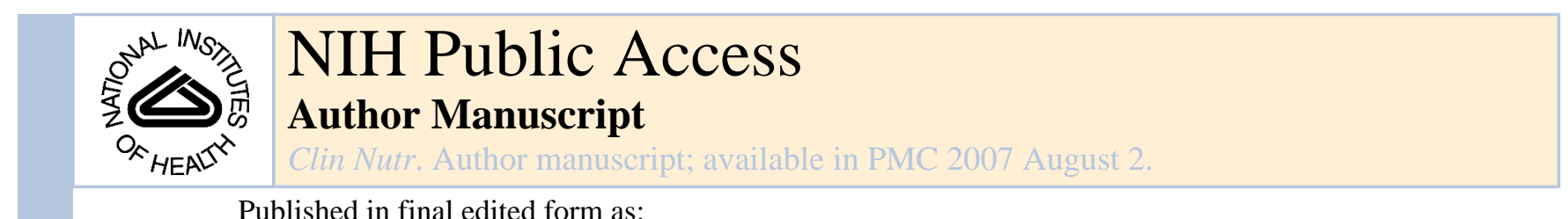

Published in final edited form as:

Clin Nutr. 2007 February ; 26(1): 166-167.

\title{
Reply to Dr. Blumenthal's Letter
}

\section{George B Kudolo}

August 28, 2006

Dear Editor:

I am writing in response to Mr. Mark Blumenthal's letter to you, regarding my paper which was published in Clinical Nutrition.

As I personally explained to Mr. Blumenthal, EGb 761 was used simply as a scientific term or abbreviation for Ginkgo biloba extract and there was no intention to ascribe the results of this study to the EGb 761 from Willmar Schwabe Pharmaceutical Co. of Karlsruhe, Germany. In the first line of the Introduction in the paper, I explained that the term EGb 761 was "coined" by this company. I, like some investigators in the literature, have used this term loosely, regrettably, simply as an abbreviation.

In the 2 papers $(1,2)$ published in your journal and in others elsewhere (3-6), I have provided the analytic constituents of our Ginkgo biloba extract to which I have ascribed our outcomes to. I believe the constituents of our extract compare favorably with the standardized 50:1 extract EGb 761.

I have provided the source of our Ginkgo extracts in other publications. In the open label studies (3-6), the Ginkgo extract, in tablet form, was supplied by Walgreens phamacy, which is found in practically every city in the United States. In the randomized, placebo-controlled trials, however, the extracts and placebos were supplied by Whole Health nutritional stores (accessible from the internet) which was supplied in the form of capsules $(1,2,7,8)$. As the principal investigator of these studies, I also take responsibility for the decision to use a vegetable-based placebo instead of an "inert compound". I believe this to be a superior design because any changes in the outcome could be ascribed to the active ingredients of the Ginkgo extract, rather than to some non-specific plant constituents, e.g. from a subjects' diet. I believe trace phytochemicals in the form of co-factors and micro-nutrients may modulate responses to herbal products and the subjects' vegetable eating habits cannot be controlled during the study. Additionally, I wanted to color-match the Ginkgo extract since study subjects may open the capsules. Moreover, the study design is a randomized, double-blind, placebo-controlled CROSS-OVER study in which each subject ingested the alfalfa "placebo" material in one cycle and the Ginkgo extract in the other. While I can see the merit in using an "inert" compound as placebo, on this issue, I respectfully disagree with Mr. Blumenthal.

In conclusion, I appreciate the vigilance of Mr. Blumenthal and his interest in our work. I hope it is understood that there was no intention to ascribe the results of these studies to the Schwabe Ginkgo extract. The results reflect outcomes from ingesting a "generic" Ginkgo biloba extract.

Thank you.

Publisher's Disclaimer: This is a PDF file of an unedited manuscript that has been accepted for publication. As a service to our customers we are providing this early version of the manuscript. The manuscript will undergo copyediting, typesetting, and review of the resulting proof before it is published in its final citable form. Please note that during the production process errors may be discovered which could affect the content, and all legal disclaimers that apply to the journal pertain. 


\section{References}

1. Kudolo GB, Wang W, Javors M, Blodgett J. The Effect Of The Ingestion Of Ginkgo Biloba Extract (EGb 761) On The Pharmacokinetics Of Metformin In Non-diabetic And Type 2 Diabetic Subjects A Double Blind Placebo-Controlled, Crossover Study. Clin Nutr 2006;25:606-616. [PubMed: 16698134]

2. Kudolo GB, Wang W, Elrod R, Barrientos J, Haase A, Blodgett J. Short-term ingestion of Ginkgo biloba Extract does not alter whole body insulin sensitivity in non-diabetic, pre-diabetic or type 2 diabetic subjects - a randomized double-blind placebo controlled crossover study. Clin Nutr 2006;25:123-134. [PubMed: 16293352]

3. Kudolo GB. The Effect of 3-month Ingestion of Ginkgo biloba extract on pancreatic $\beta$-cell function in response to glucose loading in normal glucose tolerant individuals. J Clin Pharmacol 2000;40:647654. [PubMed: 10868316]

4. Kudolo GB. The Effect of 3-month Ingestion of Ginkgo biloba extract (EGb 761) on pancreatic $\beta$-cell function in response to glucose loading in individuals with non-insulin dependent diabetes mellitus. J Clin Pharmacol 2001;41:600-611. [PubMed: 11402628]

5. Kudolo GB, Dorsey S, Blodgett J. Effect of the ingestion of Ginkgo biloba extract on platelet aggregation and urinary prostanoid excretion in healthy and type 2 diabetic subjects. Thromb Res 2003;108:151-160. [PubMed: 12590952]

6. Kudolo GB, Wang W, Dorsey S, Blodgett J. Oral Ingestion of Ginkgo biloba Extract Reduces Thiobarbituric Acid Reacting (TBAR) Substances in Washed Platelets of Healthy Subjects. J Herbal Pharmacother 2003;4:1-15.

7. Kudolo GB, Wang W, Barrientos J, Elrod R, Blodgett J. The Ingestion of Ginkgo Biloba Extract (EGb 761) Inhibits Arachidonic Acid-Mediated Platelet Aggregation And Thromboxane $B_{2}$ Production in Healthy Volunteers. J Herbal Pharmacother 2004 2004;4:13-26.

8. Kudolo GB, Delaney D, Blodgett J. Short-term Oral Ingestion of Ginkgo biloba Extract (EGb 761) Reduces Malondialdehyde Levels in Washed Platelets of Type 2 Diabetic Subjects. Diabetes Res Clin Pract 2005;68:29-38. [PubMed: 15811563] 